\title{
Dentigerous Cyst: A Review of Literature
}

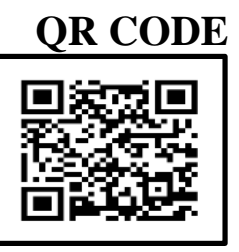

\section{SAURABH BHARDWAJ', MEHAK ANAND*2, GAZALLA ALTAF³, SAKSHI KATARIA ${ }^{4}$}

A dentigerous cyst is a developmental cyst of odontogenic origin which develops around the fully-formed crown of an unerupted tooth. The significance of keratinization in odontogenic cysts is not fully known, but keratinization is the final product of epithelial cell differentiation. However, dentigerous cysts, thought to arise from reduced enamel epithelium, are products of end cells, i.e. cells that have completed synthesis (enamel formation). It is possible that the dentigerous cyst is a primordial variant, arising from more primitive cells of the developing enamel organ.

KEYWORDS: Dentigerous Cyst, Odontogenic Keratocyst, Enucleation, Marsupialization

\section{INTRODUCTION}

In 1962, for the first time, Gorlin and co-workers coined the term Odontogenic cysts. As per documented literature, it is considered to be the second most common (15\%) true cyst of epithelial origin found in the jaw. This particular cyst develops when a follicle separates from the crown of a developing tooth with fluid accumulation between the reduced enamel epithelium and tooth crown which forms a cystic cavity surrounding the crown of an unerupted tooth at the cemento-enamel junction. Henceforth, it is also known as follicular cyst. ${ }^{1-4}$ Dentigerous cyst is not keratinized but when keratinisation is present in the dentigerous cyst, it is known as Keratinizing Dentigerous cyst. Orthokeratinized odontogenic cyst (OOC) has specific histopathological features and clinical behaviour. Histogenesis may be from the remnants of the dental lamina or from the basal cell layer of the oral mucosal epithelium. ${ }^{5}$

Cortical expansion occurs, when the cysts enlarges in size and clinically manifested as a swelling, along with pain, though in maximum cases, it can be detected incidentally during a routine radiograph examination. ${ }^{6}$ It is a rare entity and has been reported in the world literature only three times to the best of my knowledge. Hence, it is suggested that before making final diagnosis of the cyst by histopathological examination which is utmost important and valuable diagnostic tool, we must evaluate the clinical and radiological examinations carefully and the differential diagnosis of the lesion must be taken into great consideration as this cyst may mimic many alarming life threatening conditions (Figure 1). ${ }^{7,8}$

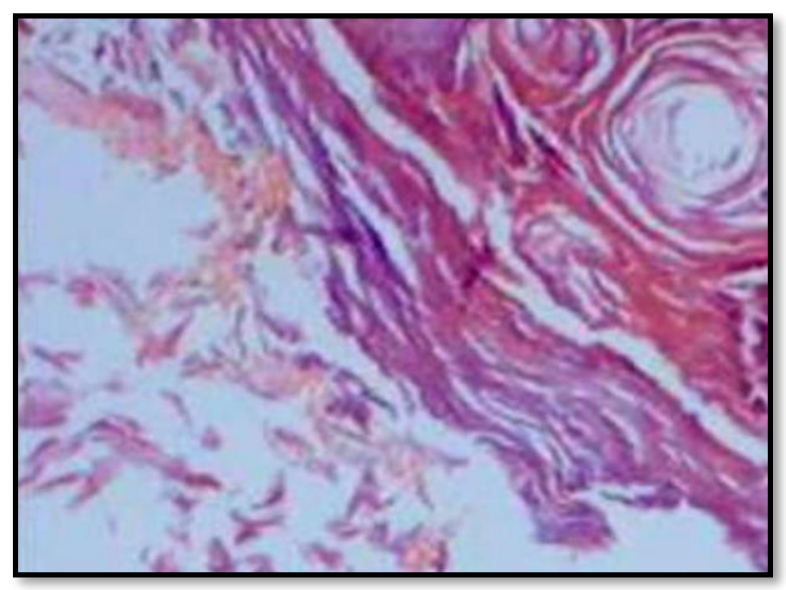

Figure 1. Microphotograph showing lamellar sheets of keratin

\section{DISCUSSION}

Odontogenic cyst is most commonly found in the 1030 years age group and may remain symptomatic throughout life and in such particular cases, it is usually diagnosed incidentally on a radiograph. There is a certain possibility that the cyst may cause pathological fracture or get secondarily infected. There are also rare incidents of malignant transformation into squamous cell carcinoma, mucoepidermoid carcinoma, or an ameloblastoma reported in literature. ${ }^{3}$ 
It is most commonly associated with crown of permanent impacted tooth, and involvements of primary teeth are infrequent. In 1963 the terminology: keratinizing and calcifying odontogenic cysts were introduced by Gold. Dentigerous cyst has been defined as one "which is attached at the cementenamel junction and encloses the crown of an unerupted tooth". 6

Dentigerous cyst is commonly seen $3^{\text {rd }} \& 4^{\text {th }}$ decades of life. In 1956, a suggestion was put forward by Philipsen to name the term Odontogenic Keratocyst $(\mathrm{OKC})$ for all Odontogenic cysts, regardless of their type and keratinization observed/seen in the epithelium.

More recently, OKC has been defined by other characteristics of the epithelium which includes basal

palisading, hyperchromatism of nuclei and cell thickness of the epithelium and not merely the presence of keratinisation alone. Whereas, the term "keratinizing odontogenic cyst" was used for any cyst showing keratinisation, regardless of their type. The significance of keratinization in odontogenic cysts has not been fully explored. The final cycle of epithelial cell differentiation results in Keratinization. As, dentigerous cysts have been thought to arise from reduced enamel epithelium [(i.e. cells that have completed synthesis (enamel formation)], there is a possibility that a dentigerous cyst is a primordial variant; arising from more primitive cells of the developing enamel organ. ${ }^{9-11}$

\section{TREATMENT}

The management is guided by the age of the patient, location and extension of the cyst. The authors have proposed various treatment modalities. The surgical procedures routinely employed are marsupialisation or enucleation.

The modified techniques for the treatment of OKC include a combination of the use of Carnoy's solution following enucleation, and bone grafts to fill the cystic cavity. As, the recurrence rate of dentigerous cyst is very low as compared to other cysts, ${ }^{1}$ cysts that are smaller in size and close to the osteomeatal complex can be removed endosopically. For ohers especially those with lateral and posterior extensions, a Caldwell-Lucor approach is recommended. The large residual bony cavities may be obliterated with bone grafts. ${ }^{3}$

\section{CONCLUSION}

Dentigerous cyst is most commonly associated with impacted tooth of the jaw i.e. $3^{\text {rd }}$ molars followed by maxillary canine, encircling the neck of crown of impacted tooth. OKC should also be considered as it has similar features to those of both dentigerous cyst and AOT.

Keratinizing dentigerous cyst is an unusual histological variant of odontogenic cyst and very rarely arises from supernumerary tooth. To the best of our knowledge, it has been cited thrice in the dental literature i.e. 1971, 2014 \& 2016. As very less information is available, the present review was attempted to add to the existing information. As it has high chances of malignant transformation, early diagnosis and intervention is utmost priority while managing them. Therefore, accurate interpretations of keratinizing odontogenic cysts are fallacious as it gives rise to erroneous radiographic picture which may also mimic other non-keratinizing odontogenic cysts. Hence, careful clinical, histopathological and radiological correlation along with molecular and immunohistochemical analysis is needed for its final diagnosis and proper treatment planning.

\section{REFRENCES}

1. Asnani S, Mahindra U, Rudagi BM, Kini Y, Kharkar VR. Dentigerous cyst with an impacted third molar obliterating complete maxillary sinus. Indian Journal of Dental Research. 2012;23(6):833.

2. Oliveira LS, Souza DO, Neves FS, Dos Santos JN, Campos PS, Crusoé-Rebello I. Uncommon dentigerous cyst related to a maxillary lateral incisor in a 03-year-old boy. Oral and maxillofacial surgery. 2012;16(4):383-8.

3. Di Pasquale P, Shermetaro C. Endoscopic removal of a dentigerous cyst producing unilateral maxillary sinus opacification on computed tomography. ENT: Ear, Nose \& Throat Journal. 2006;85(11):747-8.

4. Narain S, Gulati A. Dentigerous cyst associated with supernumerary tooth in anterior maxilla: a case report. International Journal of Clinical Dental Science. 2012;3(1):20-4.

5. Sivasankar V, Ranganathan K, Praveen B. Keratinizing dentigerous cyst. Contemporary clinical dentistry. 2014;5(1):127.

6. Gupta A, Sharma S, Malik AR. Keratinizing Dentigerous Cyst: A Review of Literature. Journal of 
Advanced Medical and Dental Sciences Research. 2018;6(3):74-6

7. Shear M, Seward GR. Cysts of the oral regions. John Wright; 1992.

8. Isser DK, Das S. Dentigerous cyst in a young boy. Indian Journal of Otolaryngology and Head and Neck Surgery. 2002;54(1):44.

9. Kraft S, Granter SR. Molecular pathology of skin neoplasms of the head and neck. Archives of Pathology and Laboratory Medicine. 2014;138(6):75987.
10. Gowda S, Viswanatha B, Junjanna P. Keratinizing Dentigerous Cyst: A Case Report and Review of Literature. Research in Otolaryngology. 2014; 3(6):858.

11. Sivasankar V, Ranganathan K, Praveen B. Keratinizing dentigerous cyst. Contemporary clinical dentistry. 2014 Jan; 5(1):127.

12. Ramakrishna A, Lambade P. Dentigerous cyst associated with ectopic canine and a supernumerary tooth: A rare occurrence. Journal of surgical technique and case report. 2013;5(2):85-8.
Source of support: Nil, Conflict of interest: None declared

\section{AUTHOR AFFILIATIONS:}

1. PG Student, Department of Oral and Maxillofacial Surgery, Santosh Dental College, Ghaziabad U.P., India

2. PG Student, Department of Paedodontics and Preventive Dentistry, Sudha Rustagi College of Dental Sciences and Research, Faridabad, Haryana, India

3. PG Student, Department of Paedodontics and Preventive Dentistry, Sudha Rustagi College of Dental Sciences and Research, Faridabad, Haryana, India 4. Senior lecturer, Department of Public Health Dentistry, Sudha Rustagi College of Dental Sciences and Research, Faridabad, Haryana, India
*Corresponding Author and Address: Dr. Mehak Anand Gg/2 Block, H. No 68C Vikas Puri, New Delhi

\section{Cite this article as:}

Bhardwaj S, Anand M, Altaf G, Kataria S. Dentigerous Cyst: A Review of Literature. Int Healthc Res J. 2019;3(2):56-58. doi: 10.26440/IHRJ/0302.05.521077 110018 